\title{
Drainage Integration of the Salt and Verde Rivers in Arizona: Initial Insight from an Electron Microprobe Investigation of Basalts.
}

\author{
Axel Wittmann ${ }^{1}$ and Ronald Dorn ${ }^{2}$ \\ 1. LeRoy Eyring Center for Solid State Science, Arizona State University, Tempe, AZ 85287, USA, \\ axel.wittmann@asu.edu \\ 2. School of Geographical Sciences and Urban Planning, Arizona State University, Tempe AZ 85287, \\ USA, ronald.dorn@asu.edu
}

The Salt and Verde River watersheds of Arizona provide much of the water supply for metropolitan Phoenix, but these river systems did not exist in the Pliocene. Lake overflow developed these throughflowing rivers [1], and this research explores the hypothesis that the overflow events occurred roughly at the same time. ICP-AES analyses of 69 basalt clasts from subsurface gravel deposits revealed a variety of distinctive trace element signatures (Dorn, unpublished data); trace elements of 2 types of basalt from the basal layer of the river gravels (named Type A and B) matched basalt from within the Verde River drainage, while 1 clast matched a potential basalt source (named WH) within the Salt River drainage.

Our samples are 10 basalt clasts 1 to $2 \mathrm{~cm}$ in size (Fig. 1): Type A and Type B consists of 3 samples each, collected from: source location, stream terrace gravel, and subsurface gravel. Type WH consists of 4 samples, 2 from the source location and 2 from subsurface gravel. We determined the petrography and mineral phase chemistry of these basalt clasts with a JEOL JXA-8530F field emission electron microprobe at Arizona State University’s LeRoy Eyring Center for Solid State Science.

Macroscopically, all clasts of the three types of basalts share petrographic similarities (Fig. 1): Type A appears fairly homogenous and fresh without vesicles; Type B exhibits large vesicles up to $3 \mathrm{~mm}$ in diameter; Type WH is characterized by $1 \mathrm{~mm}$, euhedral domains that are bright orange. In microscopic view, all clasts display assemblages of plagioclase laths, subhedral pyroxene, euhedral magnetite that typically exsolved lamellae of ilmenite, and small, interstitial domains of melt mesostasis. Feldspar core compositions in the A, B and WH basalt samples overlap with averages indicating compositions of labradorite and andesine. Type A feldspar is present as subhedral, up to $500 \times 150 \mu \mathrm{m}$ laths, although average sizes are only 150 x $20 \mu \mathrm{m}$; these crystals have mostly labradorite cores and $10 \mu \mathrm{m}$ thick, Kenriched rims. Type B feldspar typically occurs as clusters of $100 \times 20 \mu \mathrm{m}$ laths with andesine cores and $\sim 5 \mu \mathrm{m}$ thick rims enriched in K (up to Or40). Samples B2 and B3 contain several 0.3 to 1 mm oligoclase xenocrysts with $0.3 \mathrm{~mm}$ thick, concentric overgrowth rims of andesine to anorthoclase and skeletal ilmenite laths. Type WH feldspar forms up to $250 \times 80 \mu \mathrm{m}$ andesine-oligoclase laths with $5 \mu \mathrm{m}$ thick rims enriched in K but typically occurs as clusters of much smaller, $50 \times 10 \mu \mathrm{m}$, zoned crystals. Samples WH3 and WH4 contain 0.5 to $1 \mathrm{~mm}$ long andesine to anorthoclase xenocrysts with 50 to $200 \mu \mathrm{m}$ thick overgrowth rims of andesine and mafic minerals. Pyroxene in all samples exhibits complex concentric zonations due to variations in $\mathrm{MgO}$ and $\mathrm{FeO}$ concentrations. They are mostly augite with overlapping compositional ranges; only a few analyses in samples B1, B2, and B3 indicate diopside. Type A pyroxene are $90 \mu \mathrm{m}$, equigranular, subhedral crystals with subtle zonation and relatively low compositional variation. In contrast, Type B and Type WH pyroxene occur as inequigranular assemblages of crystals $150 \mu \mathrm{m}$ and $30 \mu \mathrm{m}$ in average size with prominent compositional zonations and Type WH pyroxenes are more magnesian $(\mathrm{Mg \#}$ as mol\% $\mathrm{Mg} /(\mathrm{Mg}+\mathrm{Fe})=79)$ than the average $\mathrm{Mg \#}$ of 76 for Type $\mathrm{A}$ and Type $\mathrm{B}$. The $\mathrm{TiO}_{2}$ abundances in pyroxenes correlate positively with $\mathrm{Al}_{2} \mathrm{O}_{3}$ 
concentrations and the pyroxenes in Type $\mathrm{B}$ basalts exhibit the largest variation in $\mathrm{TiO}_{2}$ and on average higher $\mathrm{TiO}_{2}$ concentrations than pyroxenes in Types $\mathrm{A}$ and $\mathrm{WH}$. However, pyroxenes in the different clasts in each basalt type do not plot separately based on $\mathrm{TiO}_{2}$ and $\mathrm{Al}_{2} \mathrm{O}_{3}$ concentrations (Fig. 2). Olivine is only present in samples A1, A2, and A3, where it occurs as subhedral, 100 $\mu \mathrm{m}$, blocky phenocrysts (PC) with overlapping compositions of Fo57-65 with little to no signs of alteration. In samples A2 and A3, 300 to $500 \mu \mathrm{m}$ xenocryst olivines occur (Fig. 3). Their Mg-rich cores (Fo77-81) show incipient breakdown to porous alteration phases. These cores are surrounded by diffuse, cloudy, $50 \mu \mathrm{m}$-wide regions with higher mass contrast that yielded poor, non-stoichiometric totals and contain inclusions of ilmenite and magnetite. An irregular, typically $30 \mu \mathrm{m}$ wide, featureless overgrowth rim of olivine (Fo62-63, n=3) has the typical composition of phenocryst olivine. Samples B contain FeO-rich alteration phases with similar shapes and sizes than the olivine phenocrysts in samples A1, A2, and A3. However, $\mathrm{SiO}_{2}$ and $\mathrm{MgO}$ concentrations are much lower and low analytical totals suggest hydration. Type WH samples show domains larger than $1 \mathrm{~mm}$ with euhedral outlines, partly filled relict Fe-(hydro)oxide rims and phyllosilicates that may be alteration relicts of larger olivine phenocrysts. Also, Type WH clasts contain $600 \times 250 \mu \mathrm{m}$ euhedral domains of assemblages of $\sim 5 \mu \mathrm{m}$ FeO-rich phases, K- and Na-rich feldspar, and phyllosilicates that could be breakdown products of mafic mineral phases. Ilmenite laths up to $50 \times 10 \mu \mathrm{m}$ in size occur most prominently in basalt clasts of Type A and B and are rare in the Type WH clasts. Similar size acicular apatite is present in all clasts but is most abundant in Types B and WH.

Mineral phase compositions of the three basalt types recovered from outcrops beneath former overflow sills, stream terraces, and drill cores of Salt River and Verde River gravels show subtle variations in chemical character among types, intra-type variation, and petrographic similarities. This initial finding supports previous trace element chemistry results that indicate the Salt and Verde Rivers contributed basalt into the same basal layer of subsurface river gravels, thus suggesting that these river systems integrated at about the same time.

\section{References: [1] J Douglass, N Meek, RI Dorn, MW Schmeeckle, GSA Bulletin 121 (2009) 586.}
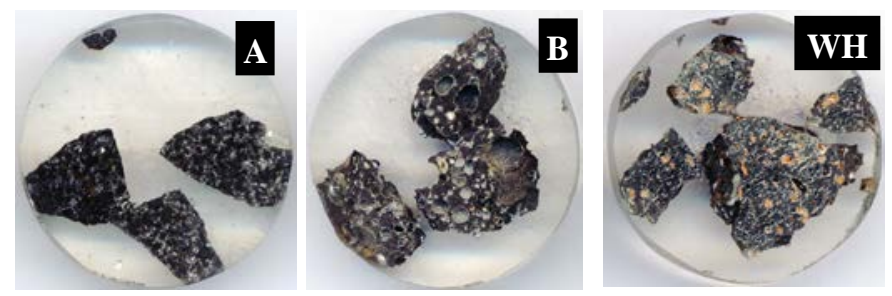

Figure 1. 1 ” $\varnothing$ mounts Type A, Type B, Type WH.

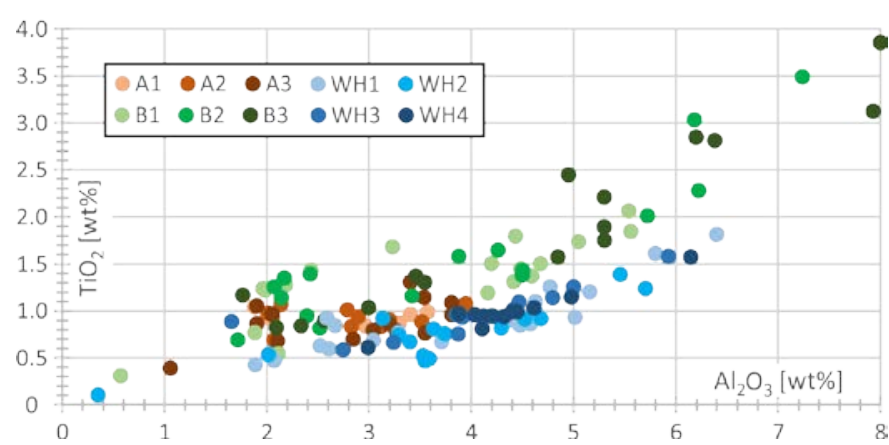

Figure 2. Basalt clast pyroxene compositions.

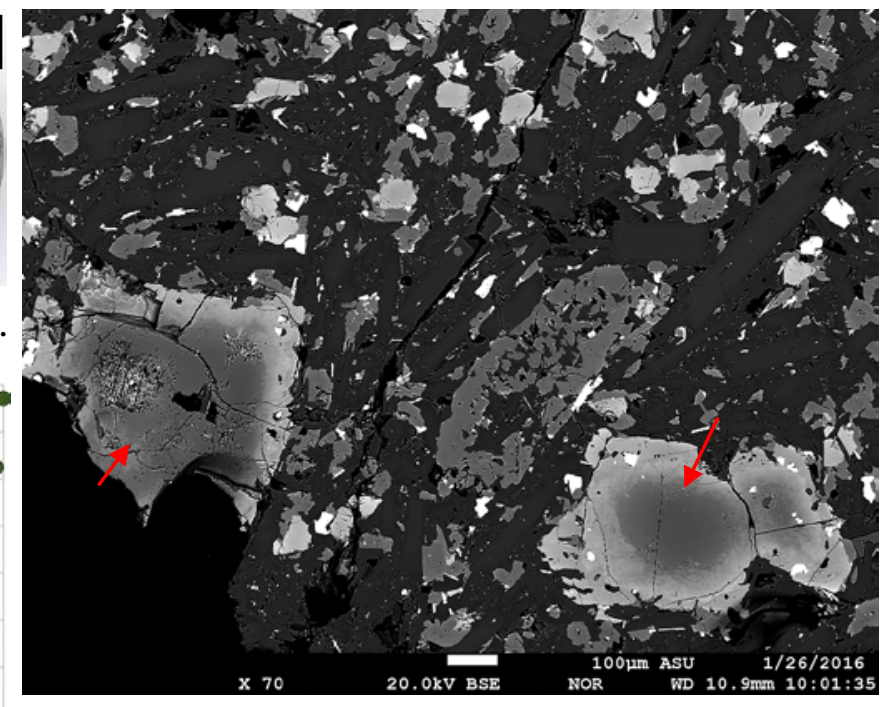

Figure 3. Backscattered electron image of sample A3 shows dark feldspar, medium grey pyroxene, light grey olivine, and bright magnetite; note two zoned olivine xenocrysts (arrows). 